Revista de Educação e Pesquisa em Contabilidade Journal of Education and Research in Accounting Revista de Educación e Investigatión en Contabilidad
REPeC, Brasília, v. 6, n. 4, art. 5, p. 419-433, out./dez. 2012 Disponível online em www.repec.org.br

ISSN 1981-8610

\title{
Um Estudo das Exigências Programáticas em Contabilidade Pública nos Concursos Públicos Organizados pelo CESPE
}

\author{
Fátima de Souza Freire \\ Doutora em Economia pela Université des Sciences Sociales Toulouse I, França. \\ Professora Associada do Departamento de Ciências Contábeis e Atuariais da Universidade de Brasilia. \\ Prédio da FACE, s. B1-02, Campus Universitário Darcy Ribeiro. 70910-900 - Asa Norte, Brasilia, DF \\ E-mail:ffreire@unb.br
}

\section{Thaise Corcino da Nóbrega}

Bacharel em Ciências Contábeis pela Universidade de Brasília.

Prédio da FACE, s. B1-02, Campus Universitário Darcy Ribeiro. 70910-900 - Asa Norte, Brasilia, DF

E-mail:thaisecorcino@gmail.com

\section{Matheus de Mendonça Marques}

Mestre em Ciências Contábeis pelo Programa Muiltiinstitucional e Inter-Regional de Pós-Graduação em Ciências Contábeis da Universidade de Brasília, Universidade Federal da Paraíba e Universidade Federal do Rio Grande do Norte. Prédio da FACE, s. B1-02, Campus Universitário Darcy Ribeiro. 70910-900 - Asa Norte, Brasilia, DF E-mail:matheus. marques123@gmail.com

\section{Ednei Morais Pereira}

Mestre em Ciências Contábeis pelo Programa Muiltiinstitucional e Inter-Regional de Pós-Graduação em Ciências Contábeis da Universidade de Brasília, Universidade Federal da Paraíba e Universidade Federal do Rio Grande do Norte. Professor Assistente da Universidade Federal de Goiás.

Campus II, Samambaia. 74001-970 - Goiânia, GO - Brasil.

E-mail:moraisednei@gmail.com

\section{Resumo}

O Conselho Federal de Contabilidade (CFC), com vistas a padronizar o conteúdo oferecido aos futuros profissionais da Contabilidade, elaborou a Proposta Nacional de Conteúdo para o Curso de Graduação em Ciências Contábeis. Com isso, o currículo adotado pelas Instituições de Ensino Superior (IES) representa um aliado às conquistas profissionais dos estudantes. A estabilidade e as condições de trabalho favoráveis atraem muitas pessoas à disputa pela ocupação de um cargo público, estando o mercado brasileiro de concursos em crescimento. Segundo a Associação Nacional de Proteção e Apoio aos Concursos (Anpac), no período de 2003 a 2009, houve um aumento de $26 \%$ no número de servidores do executivo com curso superior no Brasil. O objetivo deste estudo foi confrontar o conhecimento sugerido pelo CFC com o conteúdo demandado nas provas aplicadas em concursos públicos aos

Editado em Português, Inglês e Espanhol. Versão original em Português.

Recebido em 26/08/2011. Pedido de Revisão em 11/02/2012. Resubmetido em 20/03/2012. Aceito em 25/03/2012 por Valcemiro Nossa (Editor). Publicado em 30/11/2012. Organização responsável pelo periódico: CFC/FBC/ABRACICON.

Copyright (C 2012 REPEC. Todos os direitos, até mesmo de tradução, são reservados. É permitido citar parte de artigos sem autorização prévia, desde que seja identificada a fonte. 
profissionais de Ciências Contábeis. Pretende-se identificar quais conhecimentos da Contabilidade Pública são exigidos dos que almejam ingressar na carreira pública. Por meio de pesquisa documental, foram selecionados para amostra 561 editais de concursos exclusivos para contabilistas. Classificaram-se, de acordo com a proposta programática de conteúdo, as questões das provas realizadas pelo Centro de Seleção e de Promoção de Eventos (Cespe), no período de 2000 a 2009. Concluiu-se que as áreas da Contabilidade Pública exigidas com maior frequência abrangem os conteúdos de Patrimônio e Orçamento Público. Os resultados demonstram que a sugestão de conteúdo elaborada pelo CFC atende ao conhecimento demandado dos candidatos aos cargos públicos.

Palavras-Chave: Concurso Público. Contabilidade Pública. Proposta Nacional de Conteúdo para o Curso de Graduação em Ciências Contábeis.

\section{INTRODUÇÃO}

A aplicação de provas de concursos públicos foi baseada na Constituição Federal (CF) Brasileira de 1988 (BRASIL, 1988), que, em seu Art. $3^{\circ}$, estabelece os objetivos fundamentais da República Federativa do Brasil, entre eles: construir uma sociedade livre, justa e solidária e promover o bem de todos, sem preconceitos de origem, raça, sexo, cor, idade ou quaisquer outras formas de discriminação. O Art. 37 traz a obrigatoriedade da aplicação prévia do concurso de provas ou de provas e títulos para o acesso aos cargos públicos, estabelecendo inclusive prazos para a validade do certame. Ao oferecer igual oportunidade aos interessados, este método de avaliação possibilita o acesso à carreira pública de todos os brasileiros, e mesmo de estrangeiros, na forma da lei, que se enquadrem nos requisitos estabelecidos no edital.

No mercado de trabalho, nota-se um crescente interesse dos egressos do curso de Ciências Contábeis em cargos oferecidos nos concursos públicos do País. Isto pode ser validado em uma pesquisa sobre as expectativas dos estudantes, demonstrando que mais de $40 \%$ de alunos iniciantes de Ciências Contábeis almejavam uma vaga no serviço público (LAGIOIA et al., 2007). A relação existente entre as vagas e suas respectivas demandas tem retratado um ambiente cada vez mais competitivo. No ano de 2006, o concurso para o preenchimento de vagas do Ministério Público da União (MPU) recebeu a inscrição de 397.984 candidatos; em 2010, registrou mais de 750 mil inscritos.

A posição atual do mercado relacionado com concursos públicos também é de expansão. Isso pode ser comprovado não só pela frequência de anúncios de cursos preparatórios veiculados em jornais, quanto também, pelo vasto material, como apostilas e livros especificamente voltados para concursos, que estão à disposição daqueles que desejam ingressar na carreira pública. Esse mercado também tem atraído investidores, pois o setor cresceu em média 40\% nos últimos oito anos (KOIKE, 2009). Para atender ao contingente, as instituições investem na expansão. No Brasil são movimentados em torno de R $\$ 30$ bilhões ao ano no segmento de concursos, de acordo com a Associação Nacional de Apoio aos Concursos (PIMENTEL, 2010).

Para Marion e Santos (2000), a profissão contábil tem se tornado cada vez mais atraente devido à alta remuneração, muitas vezes maior do outras profissões tidas como "nobres", e à demanda do mercado de trabalho, que aumenta a oferta por profissionais dessa área. A demanda por profissionais capacitados para exercerem uma função pública está em crescimento. Entre 2000 a 2009, período analisado pela pesquisa, o Centro de Seleção e de Promoção de Eventos (Cespe) realizou e concluiu 561 concursos. No ano de 2006, 89 seleções foram concluídas, um aumento equivalente a $81 \%$ em relação ao ano anterior. Do total de concursos realizados no período, 216 exigiam do candidato, independente da formação requerida, o conhecimento em alguma área de Contabilidade Pública, ou seja, 37\% dos certames aplicados pelo Cespe fizeram essa exigência.

Diante da relevância que os tópicos abordados pelas disciplinas de Gestão de Finanças Públicas e Contabilidade Aplicada ao Setor Público ocupam no plano de estudo para o alcance de uma função pública, o presente trabalho tem como objetivo responder à seguinte questão: de que forma o conteúdo proposto pelo Conselho Federal de Contabilidade (CFC) para a área de Contabilidade Pública atende às exigências das provas de concursos públicos aplicadas aos profissionais da Contabilidade? 
A justificativa desta pesquisa, ligada à análise de conteúdo da disciplina de Contabilidade Pública e concurso público, sustenta-se na constatação de que a avaliação é aspecto merecedor de atenção. Cornachione Júnior e Guerreiro (2007), por exemplo, observaram as discussões acerca da qualidade, confiabilidade e isenção de determinados instrumentos de avaliação, além de analisar relações entre variáveis ligadas às provas formais, tempo e desempenho do aluno, conduzindo a pesquisa para disciplinas da área de informática e sistemas. Logo, o presente estudo contribui para possíveis reflexões aos acadêmicos e envolvidos nas elaborações de provas quanto às distorções, ou não, existentes no processo de avaliação e de aprendizado dos alunos e candidatos aos concursos públicos.

Além disso, Frezatti et al. (2006) analisaram a existência de um elo entre o perfil dos estudantes (em termos de atitudes e aspirações) e seu desempenho em matérias do curso de contabilidade. Os resultados mostram que as palavras professor, conteúdo, bibliografia, grupo e tempo têm um impacto sobre o desenvolvimento do aluno. Dessa maneira, as aspirações podem exercer influências positivas sobre o aprendizado de suas aulas. Por isso, para pensar o ensino superior requer que se visualize a educação como instância social da instituição universitária que a administra e que sofre interferências dos aspectos políticos, econômicos, sociais e culturais (LAFFIN, 2002).

Para responder aos questionamentos, a pesquisa utilizou como principal fonte de informação os editais e provas dos concursos voltados especificamente para os profissionais de Ciências Contábeis realizados pelo Cespe entre os anos 2000 e 2009. O conteúdo proposto pelo CFC para as disciplinas de Gestão de Finanças Públicas e Contabilidade Aplicada ao Setor Público foi dividido em oito subgrupos e posteriormente classificaram-se os itens constantes no edital e as questões aplicadas aos candidatos de acordo com o conteúdo abordado, buscando identificar quais as áreas da Contabilidade Pública são mais exigidas.

\section{CONTABILIDADE PÚBLICA}

A Contabilidade Pública brasileira fundamenta-se na Lei n. ${ }^{\circ}$ 4.320/1964 (BRASIL, 1964), que estatui normas gerais de Direito Financeiro para a elaboração e controle dos orçamentos e balanços da União, dos Estados, dos Municípios e do Distrito Federal. A referida lei, em seu Art. 85, define que os serviços de contabilidade serão organizados de forma a permitirem o acompanhamento da execução orçamentária, o conhecimento da composição patrimonial, a determinação dos custos dos serviços industriais, o levantamento dos balanços gerais, a análise e a interpretação dos resultados econômicos e financeiros. O campo de atuação da Contabilidade Pública abrange as pessoas jurídicas de Direito Público interno, bem como o de algumas de suas entidades vinculadas - fundações públicas, estas quando utilizam recursos do Orçamento Público (PISCITELLI e TIMBO, 2009).

O CFC aprovou, em 21 de novembro de 2008, as Normas Brasileiras de Contabilidade Aplicadas ao Setor Público (NBC T16), que define Contabilidade Aplicada ao Setor Público como o ramo da Ciência Contábil que aplica, no processo gerador de informações, os Princípios Fundamentais de Contabilidade e as normas contábeis direcionados ao controle patrimonial de entidades do setor público. Martins (2008) atenta para a mudança do objeto de estudo da Contabilidade Pública:

A ênfase passa a ser o patrimônio como objeto de estudo da contabilidade enquanto ciência. O orçamento deixa de ser o protagonista da história da administração pública para se tornar um coadjuvante importante que trata do fluxo de caixa do Governo com base em autorização legislativa para arrecadar receitas e realizar despesas. A mudança é grande e os profissionais de Contabilidade do serviço público terão que ficar preparados para essa virada de postura. Todos os fatos administrativos serão examinados e registrados não porque tem origem no orçamento, mas sim porque produzem alterações em algum elemento do ativo, passivo e patrimônio líquido. 
A Contabilidade Pública não tem como papel principal apenas a escrituração e os registros das entidades públicas. $\mathrm{O}$ controle e o acompanhamento da gestão, bem como a observação quanto à legalidade dos atos emanados da aplicação de recursos públicos também abrangem os objetivos desse eixo da Contabilidade.

Portanto, todos os profissionais de Ciências Contábeis que buscam exercer um cargo ou emprego público devem ter em mente que a demanda por posturas menos tradicionais está progredindo e que o desafio das mudanças e aplicabilidade das normas voltadas para o setor público estará presente em sua tão sonhada carreira. Cabe a este futuro servidor público empregar meios no alcance de novas habilidades que o capacite a enfrentar esses novos desafios.

\section{CURRÍCULO E A PROPOSTA NACIONAL DE CONTEÚDO PARA O CURSO DE GRADUAÇÃO EM CIÊNCIAS CONTÁBEIS}

Se a partir de um processo de seleção adequado origina-se uma correta escolha de pessoal, devidamente qualificado às atribuições do cargo, analisar esse processo torna-se relevante (SANTANA ET AL., 2008). Portanto, para que todos realmente tenham igualdade ao participar desse processo de seleção, a educação prévia desses profissionais candidatos também deve estar sob análise constante e acurada das representações responsáveis pela melhoria da profissão.

O papel que a universidade exerce sobre o desenvolvimento profissional do aluno não é somente o de transmissor de conhecimento técnico, mas também o de formação de um profissional possuidor de senso crítico e capacidade de análise, e ainda o de ser favorável às inovações no seu campo de atuação. Para Cardoso et al. (2006), o novo perfil do profissional contábil exige que ele tenha que se conscientizar como co-gestor da empresa. A Lei n. ${ }^{\circ}$ 9.394, de 20 de dezembro de 1996, estabelece as diretrizes e bases da educação nacional e, no Art. $1^{\circ} \S 2^{\circ}$, estabelece que a educação escolar deverá vincular-se ao mundo do trabalho e à prática social. A referida Lei assegura ainda, em seu Art. $53 \S 2^{\circ}$, que as universidades no exercício de sua autonomia poderão fixar os currículos dos seus cursos e programas, observadas as diretrizes gerais pertinentes.

A integração do indivíduo e da sociedade é obtida por meio da formação profissional, e o instrumento pedagógico utilizado para o alcance desse objetivo é o currículo e mais, especificamente, pela adoção de um currículo que corresponda à realidade de seu campo de atuação (Silva, 2008) e o ensino deve-se adaptar à prática ao ambiente globalizado dos negócios em que está inserido (HOWIESON, 2003). Por essa razão, em favor do desenvolvimento profissional do estudante, o currículo deve representar as exigências do mercado de trabalho e moldado para atender às reais necessidades que serão demandadas do novo profissional pela sociedade. Leite Filho e Slomski (2003) defendem que o currículo é o instrumento formador da identidade profissional do aluno, que, ao articular os conteúdos didáticos, fornece as competências necessárias e o embasamento teórico que determinará o seu futuro profissional.

Segundo o Conselho Nacional de Educação, pela Resolução CNE n. ${ }^{\circ}$ 10/04, o curso de graduação em Ciências Contábeis deve ensejar condições para que o futuro contabilista seja capacitado a compreender as questões científicas, técnicas, sociais, econômicas e financeiras, em âmbito nacional e internacional e nos diferentes modelos de organização; a apresentar pleno domínio das responsabilidades funcionais envolvendo apurações, auditorias, perícias, arbitragens, noções de atividades atuariais e de quantificações de informações financeiras, patrimoniais e governamentais, com a plena utilização de inovações tecnológicas; e a revelar capacidade crítico-analítica de avaliação, quanto às implicações organizacionais com o advento da tecnologia da informação.

A proposta nacional de conteúdo para o curso de graduação em Ciências Contábeis é uma iniciativa do CFC, que busca harmonizar o ensino da Contabilidade em todas as Instituições de Ensino Superior (IES) no Brasil. A formulação de uma proposta nacional de matriz curricular possibilita minimizar as divergências decorrentes das diversas matrizes existentes nos cursos superiores de Ciências 
Contábeis. A segunda edição elaborada e publicada em 2009 tem por objetivo levar às IES, aos coordenadores de curso e aos professores um trabalho de pesquisa que apresente sugestões de disciplinas que devam compor a grade curricular dos cursos de Ciências Contábeis no Brasil, com um conteúdo aplicável nas modalidades presencial, semipresencial e a distância. Entretanto, como o currículo deve ser reflexo das exigências do mercado, o CFC adverte que o currículo proposto é flexível e deve ser ajustado conforme o mercado de trabalho na qual a instituição de ensino esteja inserida.

Ott e Pires (2010) comparam o currículo proposto pela CNE 10/2004, com as estruturas curriculares propostas por organismos internacionais como o International Federation of Accountants (IFAC), United Nations Conference on Trade and Development (ISAR/UNCTAD), American Institute of Certified Public Accountants (AICPA) e Accounting Education Change Commission (AECC). Os autores concluíram que, apesar de haver algumas diferenças, a proposta considera as necessidades do mercado de trabalho, assim como os organismos internacionais. Tal constatação ressalta ainda mais a importância dessa resolução, considerando que ela está alinhada às propostas internacionais.

O currículo proposto pelo CFC às IES divide as disciplinas em quatro grupos de conteúdo: conteúdo de formação básica, conteúdo de formação profissional, conteúdo de formação teórico-prática e conteúdo de disciplinas optativas. As disciplinas que compõem cada um dos grupos estão separadas por eixo temático. No conteúdo de formação básica estão presentes as disciplinas que estão fora do eixo contábil, mas que são de fundamental importância na formação do profissional contábil, entre elas: Ética e Legislação Profissional, Administração e Economia. Riccio e Sakata (2004), ao compararem o currículo das IES Brasileiras à proposta curricular da ISAR/UNCTAD, tida como estrutura ideal, e às grades curriculares de universidades portuguesas, concluíram que o bloco de conhecimentos administrativos é o que apresenta maior alinhamento com as instituições internacionais.

O CFC explicita que o conteúdo de formação profissional compreende os estudos específicos atinentes à teoria da Contabilidade, incluindo domínio das atividades atuariais e quantificações de informações financeiras, patrimoniais, governamentais e não governamentais, de auditorias, perícias, arbitragens e controladoria, com suas aplicações peculiares aos setores público e privado. O conteúdo de formação teórico-prática refere-se a estágio curricular supervisionado, atividades complementares, estudos independentes, conteúdos optativos e práticas em laboratórios de informática usando softwares atualizados para contabilidade. Por fim, no conteúdo de disciplinas optativas constam as disciplinas que poderão ser escolhidas e inseridas na matriz curricular, tais como contabilidade para segmentos específicos (cooperativas, seguradoras, consórcios, hospitais, hotéis, entidades desportivas, etc.). No Quadro 1 a seguir, estão presentes os grupos de conteúdo e o total da carga horária sugerida para cada um deles:

\begin{tabular}{|l|c|}
\hline \multicolumn{2}{|c|}{ Proposta de componentes curriculares para o curso de Ciências Contábeis } \\
\hline \multicolumn{1}{|c|}{ Grupo } & Carga horária \\
\hline Conteúdo de Formação Básica & 900 horas \\
\hline Conteúdo de Formação Profissional & 1680 horas \\
\hline Conteúdo de Formação Teórico-Prática & 420 horas \\
\hline Conteúdo de Disciplinas Optativas & Mínimo de 180 horas \\
\hline
\end{tabular}

\section{Quadro 1: Proposta de Componentes Curriculares}

Fonte: Elaboração própria a partir de dados da Proposta Nacional de Conteúdo para o Curso de Graduação em Ciências Contábeis (CFC,2009).

A partir da definição de concurso público e do campo de atuação da Contabilidade Pública, foi estabelecida uma comparação cujo objetivo é verificar de que maneira a proposta elaborada pelo CFC para as disciplinas de Gestão de Finanças Públicas e Contabilidade aplicada ao Setor Público atende às exigências das provas de concurso aplicadas aos profissionais de Ciências Contábeis. 


\section{METODOLOGIA}

O trabalho foi realizado por meio de pesquisa bibliográfica e documental, tendo como principais fontes de informações: livros, artigos, editais, provas de concursos e a Proposta Nacional de Conteúdo para o Curso de Graduação em Ciências Contábeis. Trata-se de uma pesquisa descritiva, pois busca a enumeração e ordenação dos dados sem o objetivo de comprovar hipóteses exploratórias, além de descrever as características de determinada população (ALMEIDA et al., 2009). É considerada também de análise de conteúdo uma vez que utiliza uma técnica para o tratamento de dados que visa identificar o que está sendo dito a respeito de determinado tema (VERGARA, 2006).

A pesquisa abrange todos os concursos realizados e finalizados pelo Cespe entre os anos 2000 e 2009. A acessibilidade às informações oferecida por sua banca organizadora foi requisito fundamental para a escolha, além do volume de concursos realizados e concluídos no período e, também, pela relevância da sua atuação no mercado. Do universo descrito na Tabela 1, infere-se que o Cespe deteve a responsabilidade de realização de $64 \%$ do total de concursos aplicados no período das bancas organizadoras citadas.

Tabela 1: Total de concursos realizados e encerrados pelas principais bancas organizadoras - Período 2000 a 2009

\begin{tabular}{c|c}
\hline Banca organizadora & Concursos realizados e encerrados \\
\hline Cespe & 561 \\
\hline FCC & 85 \\
\hline Cesgranrio & 75 \\
\hline Funiversa & 71 \\
\hline ESAF & 59 \\
\hline FGV & 24 \\
\hline Total & $\mathbf{8 7 5}$ \\
\hline
\end{tabular}

Fonte: Elaboração própria a partir de dados disponíveis nos sítios das bancas organizadoras

A coleta de dados foi realizada por meio da internet, a partir dos editais e provas disponíveis no sítio da instituição www.cespe.unb.br. Dos concursos realizados e concluídos no período, foram selecionados os que exigiam do candidato o conhecimento em alguma extensão da Contabilidade Pública. Desses concursos, fazem parte da amostra analisada, os que tiveram como requisito para a investidura no cargo o diploma de graduação em Ciências Contábeis, ou seja, o acesso aos cargos deu-se restritamente aos contabilistas. Foi analisado um período de 10 anos de atuação do Cespe em concursos públicos (2000 a 2009), dado que a disponibilidade de informações a respeito de certames anteriores a 2000 não são tão completos quanto aqueles que foram analisados.

De posse dos editais, classificou-se cada tópico exigido em um subgrupo de conhecimentos da Contabilidade Pública, conforme a proposta de conteúdo apresentada pelo CFC. O mesmo procedimento foi adotado para classificar as questões das provas que abordavam o tema Contabilidade Pública. Foram quantificados o número de tópicos exigidos e de questões em cada subgrupo, conforme será apresentado na seção seguinte.

\section{ANÁLISE DE DADOS}

Entre 2000 e 2009, foram realizados e concluídos pelo Cespe 561 concursos para os mais diferentes níveis de formação, cargos, órgãos e regiões distribuídos, conforme a Tabela 2. 
Tabela 2: Total de concursos realizados e encerrados - Período 2000 a 2009

\begin{tabular}{c|c|c}
\hline Ano & Total de Concursos realizados e encerrados & $\mathbf{\%}$ \\
\hline 2000 & 20 & 3,57 \\
\hline 2001 & 29 & 5,17 \\
\hline 2002 & 44 & 7,84 \\
\hline 2003 & 75 & 13,37 \\
\hline 2004 & 83 & 14,80 \\
\hline 2005 & 49 & 8,73 \\
\hline 2006 & 89 & 15,86 \\
\hline 2007 & 58 & 10,34 \\
\hline 2008 & 82 & 14,62 \\
\hline 2009 & 32 & 5,70 \\
\hline Total & $\mathbf{5 6 1}$ & $\mathbf{1 0 0}$ \\
\hline
\end{tabular}

Fonte: Elaboração própria a partir de dados de editais disponíveis em www.cespe.unb.br

No ano 2000, ocorreram 20 seleções. A partir de então, a realização de concursos públicos não sofreu redução, atingindo um total de 83 seleções em 2004, o que corresponde um aumento de 75,9\%. O número de certames promovidos pelo Cespe em 2006 representa o equivalente a 15,86\% do total de concursos realizados entre os anos de 2000 e 2009, o maior percentual entre o período analisado. Comparando com o ano anterior (2005), corresponde a um aumento de cerca 37,08\%. Diferentemente, entre os períodos de 2008 e 2009, houve uma redução de 63,41\%. Apesar da considerável redução no número de concursos realizados e encerrados, destaca-se o fato de que na data de realização desta pesquisa ainda encontrava-se em aberto, ou seja, em processo de convocação dos aprovados, um total de 31 concursos realizados em 2009, o que diminui esse percentual para 23,17\%.

Observa-se um aumento do número de concursos em 2002, 2004, 2006 e 2008, que pode ser explicado em uma análise conjunta com a Cronologia das Eleições no Brasil realizado pelo Tribunal Superior Eleitoral (2010), devido à ocorrência de eleições para cargos dos Poderes Executivo e Legislativo, que de acordo com a Lei n. ${ }^{\circ}$ 9.504, de 30 de setembro de 1997, restringe-se apenas a nomeação dos concursados de três meses anteriores às eleições até a nomeação dos eleitos.

Entre as informações contidas nos editais, está o objeto de avaliação na qual constam os conhecimentos e habilidades desejáveis do candidato à vaga. Dos 561 concursos realizados e encerrados pelo Cespe, 216 (38,5\%) concursos exigiam o conhecimento em Contabilidade Pública para o cumprimento das atribuições relativas a algum cargo listado no edital. Confirma-se a relevância da disciplina para o mercado de trabalho no âmbito público, como também para a Proposta Nacional de Conteúdo para o Curso de Graduação em Ciências Contábeis elaborada pelo CFC.

Em um concurso específico, há a possibilidade de oferta de mais de um cargo para as mais diversas áreas de atuação, variando para cada um deles, o salário, o número de vagas, o conteúdo exigido do candidato e as atribuições relativas ao cargo em questão. Por exemplo, o concurso realizado para a Anatel, em 2008, ofertou 17 cargos diferentes; desse total, 3 exigiam o conhecimento em Contabilidade Pública, são eles: Analista Administrativo para profissionais graduados em Ciências Contábeis, Especialista em Regulação de Serviços Públicos de Telecomunicações para a área de Economia e esse mesmo cargo para a área de Contabilidade. Diante disso, observa-se a importância alcançada pela Contabilidade Pública para a realização de diferentes atividades no âmbito do funcionalismo público. Nas provas de concursos públicos, o conteúdo exigido em alguma área da Contabilidade Pública ocorre não somente aos profissionais de Ciências Contábeis como também aos candidatos de outras áreas, como, por exemplo, Administração, Ciências Econômicas e Direito. Casos insólitos foram observados, como o concurso realizado em 2006, a pedido do Ministério Público do Estado do Maranhão, que exigiu do candidato às vagas de Perito Criminal o diploma de Medicina e o conhecimento em Contabilidade Pública. 
A amostra analisada por essa pesquisa é o total de cargos ofertados nos 216 concursos públicos realizados, que exigiu do candidato algum conhecimento prévio em Contabilidade Pública. A Tabela 3 mostra, além do número total de cargos ofertados no período, aqueles que exigiam o diploma de graduação em Ciências Contábeis e os que exigiam o diploma em outras áreas.

Tabela 3: Total de cargos que exigiam contabilidade pública - Período 2000 a 2009

\begin{tabular}{c|c|c|c}
\hline Ano & $\begin{array}{c}\text { Cargos que exigiam } \\
\text { diploma de Contabilidade e } \\
\text { Contabilidade Pública }\end{array}$ & $\begin{array}{c}\text { Cargos que exigiam } \\
\text { diploma de outras áreas e } \\
\text { Contabilidade Pública }\end{array}$ & $\begin{array}{c}\text { Total de cargos } \\
\text { que exigiam } \\
\text { Contabilidade Pública }\end{array}$ \\
\hline 2000 & 1 & 6 & 7 \\
\hline 2001 & 0 & 8 & 15 \\
\hline 2002 & 6 & 25 & 33 \\
\hline 2003 & 8 & 64 & 93 \\
\hline 2004 & 12 & 27 & 39 \\
\hline 2005 & 31 & 49 & 29 \\
\hline 2006 & 8 & 21 & 83 \\
\hline 2007 & 26 & 57 & 33 \\
\hline 2008 & 10 & 23 & $\mathbf{4 2 0}$ \\
\hline 2009 & $\mathbf{1 3 1}$ & $\mathbf{2 8 9}$ & 80 \\
\hline Total & 29 & 9 & 83 \\
\hline
\end{tabular}

Fonte: Elaboração própria a partir de dados de editais disponíveis em www.cespe.unb.br

De acordo a Tabela 3, 31\% do total de cargos que exigiam do candidato o conhecimento em Contabilidade Pública eram voltados especificamente para profissionais graduados em Ciências Contábeis, o que demonstra uma reserva de mercado para os contadores na área pública. Incluem-se nos outros $69 \%$ os cargos que permitem o ingresso por profissionais de qualquer área de atuação.

O total de vagas preenchidas entre os anos de 2000 e 2009 que demandavam do candidato o conhecimento prévio em Contabilidade Pública equivaleu a 9.143 vagas, entretanto esse número pode ser maior, visto que vários órgãos utilizavam o concurso público para formar seu cadastro reserva. Nesse caso os candidatos com classificações posteriores ao número de vagas ficaram à disposição do órgão e dependendo da rotatividade do cargo havia possibilidade de serem convocados ao longo do prazo de validade do concurso. O prazo máximo é de até 2 anos, podendo ser prorrogado uma vez, por igual período, conforme Art. 37, inciso III da CF de 1988. Do total de vagas ofertadas, 943 (10,32\%) foram preenchidas especificamente por profissionais graduados em Ciências Contábeis. O cenário atual favorece os profissionais graduados em Ciências Contábeis e os estudantes que pretendem seguir carreira pública.

Por essa razão, a análise da proposta de currículo, elaborado pelo CFC e colocado à disposição das IES, é importante. Deve-se buscar entender como a padronização do currículo do curso de Ciências Contábeis auxilia na formação do futuro profissional e no alcance de seus objetivos. O currículo proposto pelo CFC pode ser considerado como currículo mínimo a qualquer Instituição de Ensino Superior, ou seja, como o núcleo de matérias indispensáveis para uma adequada formação profissional.

As disciplinas de Gestão de Finanças Públicas e Contabilidade Aplicada ao Setor Público estão inseridas no grupo de Conteúdo de Formação Profissional. A disciplina de Gestão de Finanças Públicas possui carga horária de 60 horas e os objetivos a serem alcançados pelos estudantes, segundo o CFC (2009) são: compreender os fundamentos e os princípios que norteiam a formulação e implementação do atual arcabouço institucional e das práticas de gestão das finanças públicas no Brasil a partir do reconhecimento dos principais instrumentos adotados no ciclo de gestão dos recursos públicos 
(Plano Plurianual - PPA, Lei de Diretrizes Orçamentárias - LDO, Lei Orçamentária Anual - LOA e Programação Financeira Anual); entender as principais definições e classificações relacionadas com receita e despesa públicas.

A disciplina de Contabilidade Aplicada ao Setor Público, que possui carga horária de 120 horas, tem por objetivos: compreender o arcabouço conceitual da Contabilidade aplicada ao setor público para geração de informações que orientem a tomada de decisão e a instrumentalização do controle social, a partir da escrituração, da mensuração científica dos ativos e passivos, permitindo a evidenciação que contribua para a transparência do setor público. Pretende-se também aplicar a prática contábil no setor público por meio de aprendizado teórico-prático.

Somente a carga horária de Contabilidade Aplicada ao Setor Público corresponde à mesma carga horária das disciplinas de Contabilidade Básica, Contabilidade Avançada e Contabilidade Societária. Juntamente com a disciplina de Gestão das Finanças Públicas, possuem carga horária total de 180 horas, ultrapassando todas as outras disciplinas. Diante do exposto, podemos concluir que, de acordo com o CFC, o eixo da Contabilidade Pública possui alto grau de relevância para a formação do profissional contábil, considerando a demanda de contadores públicos. Além do Governo federal, o país possui 27 estados, 5.565 municípios (IBGE, 2009) e ainda os órgãos de apoio a administração pública executiva, legislativa e judiciária.

O conteúdo proposto pelo CFC para as disciplinas de Gestão de Finanças Públicas e Contabilidade Aplicada ao Setor Público abrange os tópicos, unidades ou itens que estão relacionados no Quadro 2.

\begin{tabular}{|c|c|}
\hline \multicolumn{2}{|c|}{ Conteúdo proposto para as disciplinas de Gestão de Finanças Públicas e Contabilidade Aplicada ao Setor Público } \\
\hline Conteúdo & Alguns tópicos, unidades ou itens abordados \\
\hline \multirow{6}{*}{$\begin{array}{l}\text { GRUPO } 1 \\
\text { Teoria das } \\
\text { Finanças Públicas }\end{array}$} & Estado e economia \\
\hline & Eficiência, Eficácia e efetividade \\
\hline & Evolução das funções do Governo. A função do Bem-Estar \\
\hline & Bens públicos, semipúblicos e privados \\
\hline & Conceito de déficit público; financiamento do déficit \\
\hline & Necessidades de Financiamento do Setor Público; Resultado Primário; Resultado Nominal \\
\hline \multirow{3}{*}{$\begin{array}{l}\text { GRUPO } 2 \\
\text { Planejamento do } \\
\text { Setor Público }\end{array}$} & O sistema atual e o processo de planejamento público Nacional \\
\hline & Plano Plurianual: Aspectos Formais, Estrutura do PPA, Elaboração do Plano Plurianual \\
\hline & Acompanhamento, avaliação e controle \\
\hline \multirow{7}{*}{$\begin{array}{l}\text { GRUPO } 3 \\
\text { Orçamento Público }\end{array}$} & Lei de Diretrizes Orçamentárias \\
\hline & Conceitos e princípios orçamentários e tipos de orçamentos \\
\hline & Processo orçamentário da Administração Pública \\
\hline & Elaboração da Lei Orçamentária Anual (LOA) \\
\hline & A programação e a classificação das despesas e das receitas \\
\hline & A execução orçamentária da receita e da despesa \\
\hline & Créditos Adicionais \\
\hline \multirow{3}{*}{$\begin{array}{l}\text { GRUPO } 4 \\
\text { Responsabilidade } \\
\text { Fiscal }\end{array}$} & $\begin{array}{l}\text { Lei de Responsabilidade Fiscal - LRF: princípios, objetivos e efeitos no planejamento e } \\
\text { no processo orçamentário }\end{array}$ \\
\hline & Anexo de Metas Fiscais \\
\hline & Anexo de Riscos Fiscais \\
\hline
\end{tabular}




\begin{tabular}{|c|c|}
\hline \multicolumn{2}{|c|}{$\begin{array}{c}\text { Conteúdo proposto para as disciplinas de Gestão de Finanças Públicas e Contabilidade Aplicada ao Setor Público } \\
\text { (continuação) }\end{array}$} \\
\hline Conteúdo & Alguns tópicos, unidades ou itens abordados \\
\hline \multirow{4}{*}{$\begin{array}{l}\text { GRUPO } 5 \\
\text { Patrimônio Público }\end{array}$} & Conceito, classificação e grupos \\
\hline & $\begin{array}{l}\text { Receita (Variações Patrimoniais Aumentativas): conceito, classificação e estágios, aspectos } \\
\text { patrimoniais, aspectos legais, contabilização, deduções, renúncia e destinação da receita }\end{array}$ \\
\hline & Dívida Ativa \\
\hline & $\begin{array}{l}\text { Despesa (Variações Patrimoniais Diminutivas): conceito, classificação e estágios, aspectos } \\
\text { patrimoniais, aspectos legais, contabilização }\end{array}$ \\
\hline \multirow{4}{*}{$\begin{array}{l}\text { GRUPO } 6 \\
\text { Plano de Contas } \\
\text { Aplicado ao Setor Público e } \\
\text { Escrituração Contábil }\end{array}$} & $\begin{array}{l}\text { Plano de Contas Aplicado ao Setor Público - PCASP: conceito, estrutura e contas do } \\
\text { ativo, passivo, variações patrimoniais aumentativas e diminutivas, resultado e controles } \\
\text { do Planejamento e Orçamento }\end{array}$ \\
\hline & Sistemas de Informações Contábeis: Subsistema de contas \\
\hline & Escrituração contábil de operações típicas do setor público \\
\hline & Registros de aspectos patrimoniais \\
\hline $\begin{array}{l}\text { GRUPO } 7 \\
\text { Demonstrações } \\
\text { Contábeis do Setor Público }\end{array}$ & $\begin{array}{l}\text { Conceitos; aspectos legais; forma de apresentação, elaboração e análise dos demonstrativos } \\
\text { da área pública }\end{array}$ \\
\hline \multirow{5}{*}{$\begin{array}{l}\text { GRUPO } 8 \\
\text { Estrutura } \\
\text { Conceitual para a } \\
\text { Contabilidade do Setor } \\
\text { Público }\end{array}$} & Princípios Fundamentais de Contabilidade sob perspectiva do Setor Público \\
\hline & Conceito, objeto, campo de aplicação, objetivos e função social \\
\hline & Princípios Contábeis \\
\hline & Normas Brasileiras de Contabilidade Aplicadas ao Setor Público (NBC TSP) \\
\hline & Interpretação da Legislação Básica Aplicada à Contabilidade do Setor Público \\
\hline
\end{tabular}

\section{Quadro 2: Conteúdo proposto para as disciplinas de Gestão de Finanças} Públicas e Contabilidade Aplicada ao Setor Público

Fonte: Proposta Nacional de Conteúdo para o Curso de Graduação em Ciências Contábeis (2009) com adaptações

A partir da análise dos conhecimentos exigidos, observou-se que o conteúdo de Orçamento Público (Grupo 3) é a subárea da Contabilidade Pública mais requerida dos candidatos, conforme os editas dos concursos públicos analisados. O segundo lugar é ocupado pelo Plano de Contas Aplicado ao Setor Público e a Escrituração Contábil (Grupo 6). O Gráfico 1 a seguir representa de forma sintetizada a representatividade de todos os grupos de conteúdo da Contabilidade Pública nos editais estudados.

\section{Cobrança de conhecimentos da Contabilidade Pública conforme editais de concursos públicos (Período 2000 a 2009)}
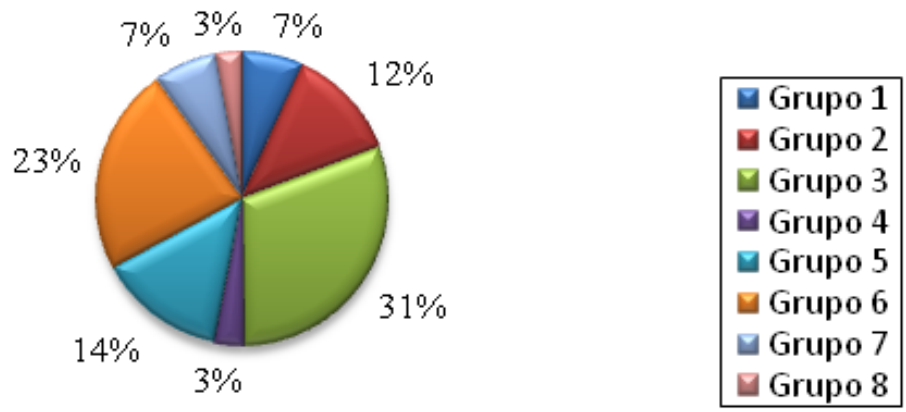

Gráfico1: Cobrança de conhecimentos da Contabilidade Pública conforme editais de concursos públicos Fonte: Elaboração própria a partir de editais disponíveis em www.cespe.unb.br (período 2000 a 2009) 
Alguns conteúdos exigidos dos candidatos, conforme os editais e as provas aplicadas, não estavam previstos explicitamente pela proposta elaborada pelo CFC e foram classificadas em grupos identificados como os que melhor correspondiam ao objeto de análise dos tópicos e questões. Como, por exemplo, questões que tratam de Auditoria do Setor Público foram enquadradas no Grupo 2, pois representam uma ferramenta de acompanhamento, avaliação e controle da gestão pública, tópico abordado por esse grupo de conteúdo. Questões a respeito do Sistema Integrado de Administração Financeira do Governo Federal (Siafi) e do Sistema Integrado de Dados Orçamentários (Sidor) abrangem o universo do Grupo 6, que correspondem a intrumentos utilizados na escrituração contábil de operações típicas do setor público e auxiliam nos registros de aspectos patrimoniais.

Partindo para a análise de conteúdo das questões das provas dos concursos públicos foi observado que, na prática, o principal conteúdo exigido dos candidatos aos cargos públicos é o de Patrimônio Público (Grupo 5), conforme observado na Tabela 4.

Tabela 4: Total de questões que exigiram o Conhecimento em Contabilidade Pública - Período 2000 a 2009

\begin{tabular}{|c|c|c|c|}
\hline Conteúdo & $\begin{array}{l}\text { Grupo de } \\
\text { Conteúdo }\end{array}$ & $\begin{array}{c}\text { Número de } \\
\text { Questões }\end{array}$ & $\%$ \\
\hline Patrimônio Público & 05 & 456 & 21,66 \\
\hline Orçamento Público & 03 & 444 & 21,09 \\
\hline Planejamento do Setor Público & 02 & 322 & 15,30 \\
\hline Plano de Contas Aplicado ao Setor Público e Escrituração Contábil & 06 & 278 & 13,21 \\
\hline Demonstrações Contábeis do Setor Público & 07 & 225 & 10,69 \\
\hline Responsabilidade Fiscal & 04 & 200 & 9,50 \\
\hline Teoria das Finanças Públicas & 01 & 124 & 5,89 \\
\hline Estrutura Conceitual para a Contabilidade do Setor Público & 08 & 56 & 2,66 \\
\hline Total & & 2.105 & 100 \\
\hline
\end{tabular}

Fonte: Elaboração própria a partir de provas disponíveis em www.cespe.unb.br

As provas aplicadas pelo Cespe, no período de 2000 a 2009, que exigiam do candidato o conhecimento em Contabilidade Pública, bem como o diploma de graduação em Ciências Contábeis, totalizaram 11.090 questões, abrangendo diversas áreas de conhecimento (como por exemplo Direito, Economia, Matemática, etc.). Desse total, 2.105 (19\%) questões exigiam do candidato o conhecimento em alguma área da Contabilidade Pública. O número de questões com conteúdo sobre Patrimônio Público (Grupo 5) representou 21,66\% deste total, o maior percentual observado. Em segundo lugar, com diferença de apenas 12 questões, o conteúdo de Orçamento Público (Grupo 3) esteve presente em 21,09\% das questões. As questões abrangem aspectos referentes a conceitos, elaboração e execução do processo orçamentário. Dentre os grupos de conteúdo analisado, a Estrutura Conceitual para a Contabilidade do Setor Público foi o assunto menos requerido, tanto pelos editais como pelas provas aplicadas aos candidatos às vagas da administração pública.

\section{CONCLUSÃO}

O presente trabalho identificou quais os conteúdos na área de Contabilidade Pública são os mais exigidos pelos concursos públicos brasileiros, buscando categorizar as questões coletadas em subgrupos e fazer um paralelo com a proposta de conteúdo indicada pelo CFC. Da análise realizada, depreende-se um foco predominante nas questões voltadas ao Patrimônio Público, questões estas que abarcavam os conceitos, classificações e estágios da Receita e Despesa Pública. O conteúdo de Orçamento Público alcançou o segundo lugar das questões mais exigidas em concursos públicos para cargos voltados especificamente 
para contadores. Entretanto esse eixo de conhecimento foi o que representou a maior frequência em editais. A relevância do tema Orçamento Público na avaliação de novos servidores se deve, entre outros fatores, pela obrigatoriedade da elaboração dos orçamentos em cada esfera da Administração, servindo como instrumento de controle e divulgação à sociedade dos programas de Governo e seu cumprimento.

Deve-se considerar que, apesar da pouca incidência de questões relacionadas à Estrutura Conceitual para a Contabilidade do Setor Público e à Teoria das Finanças Públicas, o conhecimento dessas áreas de conteúdo da Contabilidade Pública é essencial para o entendimento de outros temas e proporciona uma posição mais crítica ao futuro servidor público.

Foi observado que a proposta apresentada pelo CFC abrange a integralidade do conteúdo da disciplina de Contabilidade Pública, não apenas aqueles conhecimentos exigidos em concursos, conforme apresentado. Sugere, portanto, sua viabilidade como ementa padrão para os cursos de Contabilidade, devido a sua extensão de conteúdo, o que permite aos alunos uma visão panorâmica da área e a possibilidade de formação de ideias mais críticas e inovadoras, objetivo este primordial no mercado de trabalho atual.

Observou-se que cargos cujas atribuições correspondiam a atividades que deveriam ser desempenhadas por profissionais da área contábil são destinadas também a profissionais graduados em outras áreas, como Administração e Economia, não existindo legislação que disponha a respeito da destinação dessas vagas. $\mathrm{Na}$ análise das questões, constatou-se que havia repetição nas provas realizadas pelo Cespe, existindo casos que o texto era apenas transcrito em provas distintas, outros que somente valores eram alterados. Em razão do grande volume de concursos realizados por esta instituição, o seu banco de dados apresenta pouca variedade, no qual assuntos são abordados da mesma forma ao longo dos últimos 10 anos. Com a convergência para as Normas Internacionais de Contabilidade, esse cenário pode ser alterado nos próximos anos, posto que as exigências de conteúdo serão distintas, demandando questões diferentes e que correspondam às novas exigências que serão feitas aos futuros servidores.

Apesar de a pesquisa ter percorrido 561 editais publicados num período de 10 anos, o trabalho não se preocupou com os editais lançados por outras bancas organizadoras que não o Cespe, o que poderia ter adicionado mais 314 outros editais na amostra. Cabe ressaltar que o trabalho limitou-se à análise de apenas uma devido à indisponibilidade de informações a respeito dos concursos realizados pelas outras bancas organizadoras. Caso a pesquisa fosse realizada em todo o universo de concursos realizados, ou feita a partir de uma amostra em que constassem provas de outras bancas, a realidade seria mais bem refletida. Encontrou-se dificuldade também no enquadramento de tópicos e questões de concursos na classificação proposta pelo CFC, pois estes apresentavam, em alguns casos, interdisciplinaridade. Além disso, a definição sugerida pelo CFC sobre alguns assuntos são por demais sintetizados, o que levou a deduções acerca da classificação.

Para uma visão mais abrangente, a comparação entre a proposta de conteúdo e os conhecimentos exigidos em concursos públicos poderia ser também realizada com outras áreas do conhecimento contábil, perfazendo uma comparação integral da proposta do CFC com o que está sendo exigido nos editais de concursos públicos aos profissionais da área contábil.

\section{REFERÊNCIAS}

ALMEIDA, Kátia de; FERREIRA, Calebe da Costa; OLIVEIRA, Roberta de Souza; ALYRIO, Rovigati Danilo; SALLES, Murilo Barbosa. Análise da evolução da metodologia utilizada nos artigos publicados na revista: Contabilidade e Finanças - USP. SEMINÁRIO DE ADMINISTRAÇÃO DA USP - SEMEAD. 12. Anais... Disponível em : http://www.ead.fea.usp.br/semead/12semead/resultado/trabalhosPDF/642. pdf. Acesso em: 20/01/2011.

BRASIL. Constituição da República Federativa do Brasil. Promulgada em 05 de outubro de 1988. Disponível em: http://www.planalto.gov.br/ccivil_03/constituicao/constitui\%C3\%A7ao.htm. Acesso em: 28/05/2010. 
. Lei n. 4.320, de 17 de março de 1964. Estatui Normas Gerais de Direito Financeiro para elaboração e controle dos orçamentos e balanços da União, dos Estados, dos Municípios e do Distrito Federal. Diário Oficial (da) República Federativa do Brasil. Brasília, 23 de março de 1964. Retificada em 09 de abril de 1964 e em 03 de junho de 1964. Disponível em: http://www.planalto.gov.br/ccivil_03/Leis/ L4320.htm. Acesso em: 15/07/2010.

. Lei n. 8.666, de 21 de junho de 1993. Regulamenta o art. 37, inciso XXI, da Constituição Federal, institui normas para licitações e contratos da Administração Pública e dá outras providências. Diário Oficial (da) República Federativa do Brasil. Brasília, 22 de junho de 1993. Republicada em 06 de julho de 1994. Disponível em: http://www.planalto.gov.br/ccivil_03/Leis/L8666cons.htm. Acesso em: 11/07/ 2010.

. Lei n. 9.394, de 20 de dezembro de 1996. Estabelece as diretrizes e bases da educação nacional. Diário Oficial (da) República Federativa do Brasil. Brasília, 23 de dezembro de 1996. Disponível em: http://www.planalto.gov.br/ccivil_03/Leis/L9394.htm. Acesso em: 27 /07/2010.

. Lei 9.504, de 30 de setembro de 1997. Estabelece normas para as eleições. Diário Oficial (da) República Federativa do Brasil. Brasília, 30 de setembro de 1997. Disponível em: http://www.planalto. gov.br/ccivil_03/leis/19504.htm. Acesso em: 21/07/2010.

CARDOSO, Jorge. Luiz; SOUZA, Marcos Antonio de; ALMEIDA, Lauro. Brito. Perfil do Contador na Atualidade: um estudo exploratório. 2006. Base - Revista de Administração e Contabilidade da Unisinos. 3(3):275-284, setembro/dezembro 2006.

CORNACHIONE JR, Edgard Bruno; GUERREIRO, Reinaldo. Tempo de realização de prova e performance dos alunos: aspectos do processo de avaliação formal com base em instrumentos objetivos. BaseRevista de Administração e Contabilidade da Unisinos, 4(3):223-232, setembro/dezembro 2007.

CENTRO DE SELEÇÃO E DE PROMOÇÃO DE EVENTOS. Concursos e Seleções. Apresenta informações de concursos realizados pela instituição. Disponível em: http:/www.cespe.unb.br/. Acesso em: 10/03/2010.

CONSELHO FEDERAL DE CONTABILIDADE. Proposta Nacional de Conteúdo para o Curso de Graduação em Ciências Contábeis - 2009. Disponível em: http://www.cfc.org.br/uparq/proposta.pdf. Acesso em: 23/03/2010.

Resolução Conselho Federal de Contabilidade - CFC Nº 1.128, de 21 de novembro de 2008. Aprova a NBC T16.1. Diário Oficial (da) República Federativa do Brasil. Brasília, 25 de agosto de 2008. Disponível em: http://www.cfc.org.br/sisweb/sre/Default.aspx. Acesso em 15/07/2010.

CONSELHO NACIONAL DE EDUCAÇÃO. Resolução CNE n. 10/04, de 16 de dezembro de 2004Institui as diretrizes curriculares nacionais do curso de graduação em Ciências Contábeis, Bacharelado, e dá outras providências. Disponível em: http://www.crcsp.org.br/portal_novo/legislacao_contabil/resolucoes/Res10_cne.htm. Acesso em 27/07/2010.

ESCOLA DE ADMINISTRAÇÃO FAZENDÁRIA. Concursos Públicos. Apresenta informações de concursos realizados pela instituição. Disponível em: http://www.esaf.fazenda.gov.br/. Acesso em 01/08/2010.

LEITE FILHO, Geraldo Alemandro; SLOMSKI, Valmor. Opiniões dos alunos acerca da disciplina contabilidade governamental: Um estudo empírico em uma Universidade Pública. Contabilidade, Gestão e Governança. 2003. v. 6, n. 1. p. 79 - 99. 
FREZATTI, Fábio; MARTINS, Gilberto de Andrade; LEITE FILHO, Geraldo Alemandro. Os perfis das atitudes e aspirações dos estudantes de contabilidade e seu desempenho em uma matéria: um estudo de investigação. BBR Brazilian Business Review, v. 3, nº 1, 2006.

FUNDAÇÃO CARLOS CHAGAS. Concursos. Apresenta informações de concursos realizados pela instituição. Disponível em: http://www.concursosfcc.com.br/. Acesso em: 01/08/2010.

FUNDAÇÃO CESGRANRIO. Concursos. Apresenta informações de concursos realizados pela instituição. Disponível em: http://www.cesgranrio.org.br/inicial.html. Acesso em: 01/08/2010.

FUNDAÇÃO GETÚLIO VARGAS. Concursos.Apresenta informações de concursos realizados pela instituição. Disponível em: http://concurso.fgv.br/. Acesso em: 01/08/2010.

FUNDAÇÃO UNIVERSA. Concursos. Apresenta informações de concursos realizados pela instituição. Disponível em: http://www.universa.org.br/. Acesso em: 01/08/2010.

HOWIESON, Bryan. Accounting practice in the new millennium: is accounting education ready to meet the challenge. The British Accounting Review, v. 35, n. 2, p. 69-103, 2003.

INSTITUTO BRASILEIRO DE GEOGRAFIA E ESTATÍSTICA - IBGE. Perfil dos municípios brasileiros em 2009. Disponível em: http://www.ibge.gov.br/. Acesso em: 01/08/2010.

KOIKE, Beth Et. Al - Mercado de concursos atrai investidores. 2009. Valor Econômico Online. Disponível em: http://www.valoronline.com.br/?impresso/empresas/95/6015903/mercado-de-concursos-atrai-investidores \&scrollX $=0 \&$ scroll $Y=0 \&$ tamFonte $=$. Acesso em: 03 de setembro de 2010.

LAFFIN, Marcos. Ensino da Contabilidade: componentes e desafios. Contabilidade Vista e Revista. Belo Horizonte. v.13, n. 3. p.9-20. 2002

LAGIOIA, Umbelina Cravo. Teixeira; SANTIAGO, Hugo Leonardo Ferraz; GOMES, Rafael Barbosa; RIBEIRO FILHO, José Francisco. Uma investigação sobre as expectativas dos estudantes e o seu grau de satisfação em relação ao curso de Ciências Contábeis. 2007. Revista Contemporânea de Contabilidade. Ano 04, v.1, n. 8. p.121-138. de julho a dezembro de 2007.

MARION, José Carlos; SANTOS, Márcia Carvalho dos. Os dois lados de uma profissão. Revista Contabilidade Vista e Revista. Belo Horizonte.v. 11, n. 2, p. 3-9. 2000.

MARTINS, Lino.NBCASP: A grande reforma na Contabilidade Pública. Blog do Prof. Lino Martins da Silva. Texto publicado em 03 de dezembro de 2008. Disponível em: http://linomartins. wordpress.com/2008/12/03/nbcasp-a-grande-reforma-na-contabilidade-publica/. Acesso em: 25/07/2010.

OTT, Ernani; PIRES, Charline Barbosa. Estrutura curricular do curso de Ciências Contábeis no Brasil versus Estruturas curriculares propostas por organismos internacionais: Uma análise comparativa. Revista Universo Contábil. FURB, v. 6. n. 1. p.25-45. 2010.

PIMENTEL, Ernesto. Concurso Público: o "Boom" do momento. Associação Nacional de Proteção e Apoio aos Concursos Públicos. Disponível em: http://www.anpac.org.br/portal/index.php/artigos/82-concurso-publico-o-qboomq-do-momento. Acesso em: 26/07/2010. 
PISCITELLI, Roberto e TIMBÓ, Maria. Contabilidade pública: Uma Abordagem da Administração Financeira Pública.10 ed. Revisada, ampliada e atualizada. São Paulo: atlas, 2009.

RICCIO, Edson Luiz; SAKATA, Marici Cristine Gramacho. Evidências da globalização na educação contábil: Estudo das grades curriculares dos cursos de graduação em universidades brasileiras e portuguesas. Revista Contabilidade e Finanças - USP, São Paulo, n. 35, p. 35 - 44, maio/agosto 2004

SANTANA JUNIOR, Jorge José Barros; PEREIRA, Dimmitre Morant Vieira Gonçalves; LOPES, Jorge Expedito de Gusmão. Análise das habilidades cognitivas requeridas dos candidatos ao cargo de contador na Administração Pública Federal, utilizando-se indicadores fundamentados na visão da Taxonomia de Bloom. 2006. Revista de Contabilidade e Finanças. USP. v.19. n. 46. p.108-121. 2008.

SILVA, Mônica Ribeiro da. Currículo e competências: a formação administrativa. São Paulo: Cortez, 2008.

TRIBUNAL SUPERIOR ELEITORAL. Cronologia das eleições no Brasil 1945 - 2010. Disponível em: http://www.tse.gov.br/internet/eleicoes/cronologia.htm. Acesso em: 02 de agosto de 2010.

VERGARA, Sylvia Constant. Métodos de pesquisa em Administração. 2a Edição. São Paulo: Atlas. 2006. 